\title{
PROFIL KEMAMPUAN REPRESENTASI MAHASISWA PENDIDIKAN FISIKA UNIVERSITAS MUHAMMADIYAH PURWOREJO
}

\author{
Siska Desy Fatmaryanti ${ }^{1}$, Sarwanto ${ }^{2}$ \\ ${ }^{1}$ Progam Studi Pendidikan Fisika \\ Universitas Muhamadiyah Purworejo \\ sd_fatmaryanti@yahoo.com \\ ${ }^{2}$ Progam Studi Pendidikan Fisika \\ Universitas Sebelas Maret \\ sarwanto@fkip.uns.ac.id
}

\begin{abstract}
Abstrak
Telah dilakukan penelitian tentang profil kemampuan representasi mahasiswa pada mata kuliah listrik magnet. Subjek penelitian ini adalah mahasiswa Program Studi Pendidikan Fisika Universitas Muhammadiyah Purworejo yang berjumlah 24 orang mahasiswa semester 3 TA 2014/2015. Instrumen yang digunakan adalah lembar observasi dan tes tertulis. Hasil penelitian mendeskripsikan bahwa persentase rata-rata kemampuan representasi verbal sebesar 8,7\% (baik), 30,4\% (cukup) dan 58,6\% (kurang),kemampuan representasi visual sebesar 15,9\% (baik), 33,3\% (cukup) dan 50,8\% (kurang), sedangkan kemmpuan representasi matematis sebesar 37,5\% (baik), 39,6\% (cukup) dan 22,9\% (kurang). Sehingga dipandang perlu untuk mengenalkan model pembelajaran maupun bahan ajar dengan multi representasi kepada mahasiswa.
\end{abstract}

Kata Kunci: Kemampuan representasi

\section{Pendahuluan}

Salah satu tujuan pendidikan guru MIPA di LPTK adalah untuk menghasilkan calon guru yang berwawasan luas tentang kependidikan, memiliki kemampuan dan keterampilan yang memadai dalam merancang, melaksanakan dan mengelola kegiatan pembelajaran MIPA (Dirjen Dikti dalam Mahardika, 2011). Salah satu faktor agar mahasiswa pendidikan fisika terampil dalam mengajar atau dapat mengajar dengan efektif adalah menguasai materi (konten) fisika secara benar.

Berdasarkan hasil dokumentasi nilai Listrik Magnet mahasiswa Pendidikan Fisika UM Purworejo dari tahun 2011 sampai 2014 ditemukan $30 \%$ mendapat nilai C, $40 \%$ nilai $\mathrm{B}$ . Kenyataan ini menunjukan bahwa mahasiswa masih menemui kendala dalam menguasai konten fisika.

Penggunaan representasi dalam pembelajaran fisika dapat digunakan untuk meminimalisasi kesulitan siswa dalam belajar fisika (Dolin, 2002), juga untuk meningkatkan kualitas pembelajaran IPA (Waldrip, 2008). Representasi adalah suatu konfigurasi (bentuk atau susunan) yang dapat menggambarkan, mewakili atau melambangkan sesuatu dalam suatu cara (Goldin dalam Sarwanto). Representasi merupakan sesuatu yang mewakili, menggambarkan atau menyimbulkan obyek atau proses (Waldrip, 2008). Representasi dapat dilakukan melalui berbagai cara antara lain verbal, gambar, grafik dan matematik (Waldrip dkk, 2006).

Berbagai hasil penelitian pada mahasiswa menunjukkan bahwa umumnya mahasiswa yang performansnya bagus dalam ujian, tetapi mengalami kesulitan dalam IPA akibat ketidakmampuan memvisualisasikan struktur dan proses pada level submikroskopik dan tidak mampu menghubungkannya dengan level representasi IPA yang lain (Sarwanto, 2011). Hal ini juga dialami oleh mahasiswa pendidikan Fisika UM Purworejo.

\section{Metode Penelitian}

Subjek penelitian ini adalah mahasiswa Program Studi Pendidikan Fisika universitas Muhammadiyah Purworejo yang berjumlah 24 orang mahasiswa semester 3 TA 2014/2015. Mahasiswa semester 3 telah mendapatkan materi medan magnet dan gaya 
magnet pada mata kuliah Fisika Dasar 2 dan mendapatkan materi konsep perkalian vektor pada mata kuliah Matrik dan Ruang Vektor.
Penelitian ini menggunakan metode deskriptif, Analisis data dilakukan dengan teknik interaktif (Gambar 1).

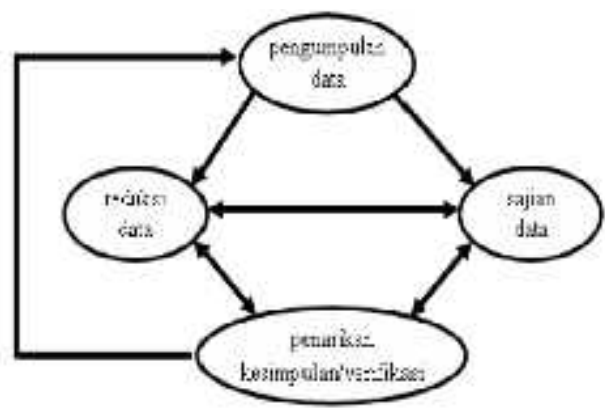

\section{Hasil dan Pembahasan}

Berdasarkan hasil observasi, wawancara dan tes tertulis mengenai kemampuan representasi mahasiswa selama penelitian didapatkan data seperti yang disajikan pada tabel 1 .

Tabel 1 Hasil persentase kemampuan representasi mahasiswa

\begin{tabular}{|c|c|c|c|}
\hline $\begin{array}{l}\text { Kemampuan } \\
\text { Representasi }\end{array}$ & Baik & Cukup & Kurang \\
\hline \multicolumn{4}{|l|}{ Representasi Verbal } \\
\hline $\begin{array}{l}\text { Frekuensi } \\
\text { berkomunikasi }\end{array}$ & $8,7 \%$ & $34,8 \%$ & $52,2 \%$ \\
\hline Isi komunikasi & $8,7 \%$ & $26,1 \%$ & $65,2 \%$ \\
\hline \multicolumn{4}{|l|}{ Representasi visual } \\
\hline $\begin{array}{l}\text { Kelengkapan } \\
\text { gambar }\end{array}$ & $13 \%$ & $47,8 \%$ & $39,2 \%$ \\
\hline Logis & $8,7 \%$ & $34,8 \%$ & $56,7 \%$ \\
\hline $\begin{array}{l}\text { Kejelasan } \\
\text { gambar }\end{array}$ & $26,1 \%$ & $17,4 \%$ & $56,5 \%$ \\
\hline $\begin{array}{l}\text { Representasi } \\
\text { matematis } \\
\text { Menyatakan } \\
\text { hubungan } \\
\text { antar variable }\end{array}$ & $29,2 \%$ & $54,1 \%$ & $16,7 \%$ \\
\hline Keruntutan & $45,8 \%$ & $25 \%$ & $29,2 \%$ \\
\hline $\begin{array}{l}\text { Kemampuan } \\
\text { adalah kemampu } \\
\text { memberikan definisi } \\
\text { Pada tabel } 1 \text { menu } \\
\text { termasuk pada kema } \\
\text { kurang. Berdasark } \\
\text { berlangsungnya perk } \\
\text { tertentu saja yang } \\
\text { mau untuk menger } \\
\text { yang cukup menarik } \\
\text { yang masuk katego }\end{array}$ & $\begin{array}{l}\text { repr } \\
\text { m } \\
\text { lari kor } \\
\text { jukan } \\
\text { apuan } \\
\text { pen } \\
\text { liahan } \\
\text { endom } \\
\text { ukakar } \\
\text { adalah } \\
\text { cukup }\end{array}$ & $\begin{array}{l}\text { sentasi } \\
\text { hasiswa } \\
\text { sep listik } \\
8,6 \% \mathrm{~m} \\
\text { presenta } \\
\text { amatan } \\
\text { lanya m } \\
\text { nasi dis }\end{array}$ & $\begin{array}{r}\text { verbal } \\
\text { untuk } \\
\text { magnet. } \\
\text { hasiswa } \\
\text { i verbal } \\
\text { selama } \\
\text { hasiswa } \\
\text { usi dan } \\
\text { Temuan } \\
\text { hasiswa } \\
\text { rekuensi }\end{array}$ \\
\hline
\end{tabular}

keaktifan memberikan definisi, namun secara isi komunikasi kurang terarah dalam artian banyak pengulangan dan memberikan contoh yang tidak sesuai.

Kemampuan representasi visual adalah kemampuan mahasiswa untuk mmvisualisasikan konsep listrik magnet yang abstrak. Data pun menunjukan 50,8\% mahasiswa termasuk kemampuan visual kurang. Kemampuan representasi visual pada materi listrik magnet disini adalah ketika mahasiswa menggambarkan garis medan listrik dan garis medan magnet, arah gaya listrik maupun magnet. Untuk mendapatkan data ini menggunakan soal tes dan wawancara untuk memperdalam penyelidikan.

Kemampuan representasi matematis adalah kemampuan mahasiswa untuk menyelesaikan persoalan kuantitatif. Kemampuan mahasiswa pada representasi ini yang termasuk kategori cukup sebanyak 39,6\% dan $37,5 \%$ sudah masuk kategori baik. Sehingga pada dasarnya mahasiswa paham secara matematis saja, namun makna fisika dibalik persamaan-persamaan dan visualisasi konsep masih kurang.

Berdasarkan wawancara dengan mahasiswa bahwa pada dasarnya mahasiswa tidak terbiasa dengan memberikan banyak representasi pada sebuah materi. Karena menurut mereka kesulitan terbesar selama pembelajaran di fisika adalah memahami matematikanya sehingga melupakan memahami konsep maupun cara memvisualisasi konsep. Padahal menurut Albe dkk (2001) pembelajaran kemagnetan akan 
JPFK, Volume 1, Nomor 1, Maret 2015 : 19-21

mengalami kesulitan jka dimulai dari matematis.

\section{Kesimpulan}

Berdasarkan hasil penelitian yang sudah dilakukan dan analisis dari pengolahan data maka penulis menarik kesimpulan yaitu persentase rata-rata kemampuan representasi verbal sebesar 8,7\% (baik), 30,4\% (cukup) dan $58,6 \%$ (kurang),kemampuan representasi visual sebesar 15,9\% (baik), 33,3\% (cukup) dan $50,8 \%$ (kurang), sedangkan kemampuan representasi matematis sebesar 37,5\% (baik), $39,6 \%$ (cukup) dan 22,9\% (kurang). Dari hasil wawancara maka dipandang perlu untuk mengenalkan model pembelajaran maupun bahan ajar dengan multi representasi kepada mahasiswa agar memperoleh pemahaman konsep listrik magnet lebih baik.

\section{Daftar Pustaka}

Albe V., Venturini P., dan Lascours J. 2001. Electromagnetic Concepts in Mathematical Representation of Physics. Journal of science Education and Technology. 10: $197-203$

Dolin, J. 2001. Representational forms in physics. Makalah Third International
Conference of the European Science Education Research Association, August.

Mahardika, I. 2011. Pengembangan bahan ajar mekanika untuk meningkatkan kemampuan representasu verbal, matematis, gambar, dan grafik mahasiswa calon guru fisika. Disertasi Doktor pada FPS UPI Bandung: tidak diterbitkan

Sarwanto. Analisis Kemampuan representasi Mahasiswa Pendidikan Sains PPS UNS. Jurnal Materi dan Pembelajaran Fisika.

Waldrip, B. (2008). Improving Learning Through Use of Representations in Science. Proceeding The $2^{\text {nd }}$ International Seminar on Science Education. UPI Bandung.

Waldrip B., Prain V., dan Carolan J. 2006. Learning Junior Secondary Science through Multi Modal Representation. Electronic Journal of Science Education. Retrived from http://ejse.southwestern.edu 